\title{
DIE NEUTRALITÄT KAMBODSCHAS - IHRE GESCHICHTE UND IHR WESEN
}

\author{
Von Manuel Sarkisyanz
}

\section{Historische Hintergründe}

Die Außenpolitik des heutigen Kambodscha entspringt historischen Erfahrungen von Landverlusten an die beiden übermächtigen Nachbarn Thailand und Vietnam, einem Ohnmachtstrauma, das im Bewußtsein vergangener Größe um so akuter wirkt. Auf dem Gebiet von Kambodscha entstand in den ersten Jahrhunderten n. Chr. der vielleicht früheste indisierte Staat in Südostasien. Auf einen eingewanderten Brahmanen namens Kaundinya geht die dynastische Úberlieferung Kambodschas zurück. „Könige des Berges“ nannte sich die protokambodschanische Dynastie von „Funan“. Obwohl ihre Inschriften in Sanskrit abgefaßt sind, gilt ihr Reich als Vorläufer Kambodschas, dessen Name sich von einem Vasallenstaat „Funans" ableitet, der im achten Jahrhundert von Java aus unterworfen wurde, aber unter Jayavarman II. 802 seine Unabhängigkeit erneuerte. Jayavarman II. führte nach hinduistischen Vorbildern, jedoch an lokale fruchtbarkeitsvitalistische Vorstellungen anknüpfend, den Kult des Gottkönigtums (des Devaraja) ein. Damit begann die Angkor-Periode (802-1432) ${ }^{1}$, von deren kultureller Bedeutung die von Jasovarman I. (889-914) gegründete Haupt- und Tempelstadt Angkor (thom) noch heute Zeugnis ablegt ${ }^{2}$. Unter Suryavarman I. (1010-1050) unterwarf Kambodscha die malaiische Halbinsel und Südteile des nachmaligen Birma und Thailands, während seine Nordgrenzen bis zum heutigen Südchina reichten. Es führte den Mahayana-Buddhismus ein, der sich mit dem königlichen Shiva-Kult der Brahmanen verflocht. Seinen Höhepunkt erreichte das mittelalterliche Kambodscha unter Jayavarman VII. (1181-1218?). Die buddhistische Ethik der Selbstidentifizierung des Herrschers mit allen Lebewesen inspirierte den Souverän zu zahlreichen wohlfahrtsstaatlichen Maßnahmen, wie beispielsweise dem Bau staatlicher Krankenhäuser. Bezeichnend ist eine erhalten gebliebene Inschrift, in der Jayavarman VII. sagt: „Der Schmerz der Untertanen und nicht das eigene Weh ist die Trauer der Könige." Darauf beruft sich auch der heutige "kambodschanische Sozialismus" des Staatschefs Norodom Sihanuk, der sich selbst als Nachkomme Jayavarmans II. versteht, obwohl die nationale Ubberlieferung - vor ihrer Bereicherung durch französische Wissenschaft - keine Erinnerung an die frühen Könige bewahrt hatte. Nach 1220 setzten die epigraphischen Quellen aus. Der seit dem vierzehnten Jahrhundert sich allgemein durchsetzende Theravada-Buddhismus, der das Kulturgepräge des heutigen Kambodscha bestimmt, mag erst durch die Thai-Eroberer verbreitet worden sein.

Im dreizehnten Jahrhundert hatte die Unterwerfung Südchinas durch die Mongolen die Völkerwanderung der Thais aus Südchina nach Hinterindien und Indochina beschleunigt. Unter anderem gehen siamesische und laotische Staatenbildungen auf sie zurück. Die Siamesen - ihr Name wird zuerst in einer kambodschanischen Inschrift erwähnt - waren anfänglich Vasallen Kambodschas und übernahmen von dort Modelle der Staatsstruktur und viel von ihrer indisierten Hochkultur. Während die überlegene indisierte Hochkultur durch Kambodschas Vermittlung sozusagen die Thais eroberte, eroberten die Thais die Kerngebiete des kambodschanischen Großreiches ${ }^{3}$. 1432 mußten die Kambodschaner (khmers) Angkor vor den

1 L. P. Briggs, The ancient Khmer Empire, Philadelphia 1962.

2 B. P. Groslier, Hinterindien, Kunst im Schmelztiegel der Rassen, Baden-Baden 1960.

3 G. Coedes, Les états hindouises d'Indochine et d'Indonésie, Paris 1964. 
anrückenden Siamesen räumen. Zwischen 1474 und 1863 wurde Kambodscha immer wieder zum Vasallen seiner vormaligen Vasallen, der Siamesen. Immer wieder erbaten kambodschanische Thronprätendenten das Eingreifen Siams. Und immer weitere Gebiete Kambodschas gingen dabei an Siam, das heutige Thailand, verloren. Mit der Schwächung des Staates verfiel zwar die in der Angkor-Periode hoch entwickelte Bewässerungsstruktur, aber günstige Naturbedingungen erlaubten noch immer, die grundlegenden Bedürfnisse mit relativ wenig Anstrengung zu befriedigen. Die Leichtigkeit des Reisanbaus und das kontemplative Ethos des Theravada-Buddhismus haben $\mathrm{zu}$ emsigen Anstrengungen wenig Anlaß gegeben. Selbst diejenigen Teile Kambodschas, in denen drei Viertel des Landes bebaubar sind, wurden nur dünn besiedelt. Etwa ein Viertel des für Reisanbau geeigneten Landes liegt brach. In weiten Teilen Kambodschas ist noch immer eine wenig intensive Bodenbebauungstechnik, die Brandrodung, üblich, ohne daß sich daraus ein Landmangel ergeben hätte 4 . So fehlt dort die Motivierung, mehr Land in Besitz nehmen zu wollen, als die eigene Familie mit Hilfe der traditionellen einfachen Technologie zu bearbeiten vermag. Umgekehrt wurde aber das unterbevölkerte Kambodscha wegen seiner Reisüberschüsse Objekt der vietnamesischen Expansion.

Aus dem chinesischen Kulturkreis hat Vietnam - nach einer über tausendjährigen Zugehörigkeit zum chinesischen Staatsverband ${ }^{5 a}$ - mit der konfuzianischen Bejahung des Ahnenkults eine Weltanschauung übernommen, die Familie und Fortpflanzung heiligt, ganz im Gegensatz zum Theravada-Buddhismus Kambodschas mit seinen Mönchsidealen. Die Bevölkerung Vietnams hat unvergleichlich mehr zugenommen als diejenige Kambodschas, wenn auch genauere Zahlen aus der Zeit vor dem französischen Protektorat nicht vorliegen. Die ebenfalls aus China übernommene landwirtschaftliche Technologie erlaubte den Vietnamesen eine wesentlich intensivere Landnutzung als die bei den Kambodschanern übliche. Doch nur ein Bruchteil der historischen vietnamesischen Gebiete sind für den Reisanbau nutzbar. So haben geopolitische Faktoren Vietnams „Drang nach Süden“ bestimmt: die Landnahme und Kolonisation der Ostküste Indochinas durch das vietnamesische Volkstum auf Kosten der schwächeren Völker mit indisierten Kulturen ${ }^{6}$. Die seit dem fünfzehnten Jahrhundert sich ununterbrochen vollziehende Expansion des vietnamesischen „Kolonialismus" hat dabei gleichzeitig die Ausbreitung des chinesischen Kulturkreises zur Folge gehabt, auf Kosten des indischen, dem die fast aufgeriebenen Chams des heutigen Zentral-Vietnam, die Laoten und die Kambodschaner, angehören.

Während die Kriege Siams mit Kambodscha eher Kämpfe um „Völker“ waren, d. h. mehr der Gewinnung von Bebauern und Tributzahlern als der Landerweiterung galten - die Bevölkerung der überrannten Gebiete wurde in großer Zahl in das eigene Territorium "verpflanzt" - weist die Expansion der Vietnamesen alle Merkmale vom „Volk ohne Raum" auf, das die eroberten Gebiete durch die eigene Bevölkerung kolonisiert und die ansässige Bevölkerung verdrängt oder beseitigt hat. Seit 1623 stehen in Saigon - einer ursprünglich kambodschanischen Siedlung - vietnamesische Garnisonen. Seitdem wurde dieses Gebiet allmählich vietnamesiert. Das restliche Kambodscha wurde - zuerst 1659 - gegenüber Vietnam tributpflichtig - als Preis für Vietnams Eingreifen in interne dynastische Rivalitätskämpfe Kambodschas. Dann kam es zwischen 1730 und 1747 zu blutigen Zusammenstößen zwischen Vietnamesen und Kambodschanern. Vietnam unterstützte jetzt die Ansprüche kambodschanischer Thronprätendenten gegen Siam. 1758 verlor Kambodscha endgültig Cochinchina an Vietnam². Dieses „Ex-Kambo-

4 Charles Fisher, Southeast Asia. A social, economic and political Geography, London 1967.

5 D. Steinberg, Cambodia, its people, its society and culture, New Haven 1957, S. 163, 191, $257,259$.

$5 \mathrm{a} \mathrm{Im} \mathrm{Gegensatz} \mathrm{zu} \mathrm{anderen} \mathrm{Staaten} \mathrm{Südostasiens,} \mathrm{die} \mathrm{bloß} \mathrm{im} \mathrm{chinesischen} \mathrm{Tributbereich} \mathrm{waren,} \mathrm{gehörte}$ Vietnam zwischen 111 v. Chr. und 939 n. Chr. zu den Provinzen des chinesischen Staates.

6 Le Thanh Khoi, Le Viet-Nam. Histoire et civilisation, Paris 1955.

7 A. Migot, Les Khmers, Paris 1960. 
dscha“, Wiege des „Funan“-Reiches, Quelle der dynastischen Tradition Kambodschas, wurde kolonisatorisch alsbald so vietnamesiert, daß es heute das Kernland Südvietnams bildet. Eine halbe Million Kambodschaner verblieben zwar dort bis heute, für ihr Stammland stellen sie jedoch eine durch Vietnam entrissene Irredenta dar. Als Süd- und Nordvietnam 1802 unter der letzten Kaiserdynastie der Nguyen vereinigt worden waren, schien das Schicksal Kambodschas besiegelt. Als führende Großmacht des voreuropäischen Indochinas nahm Vietnam 1834 das, was noch von Kambodscha geblieben war, in Besitz und behielt es bis 1845 unter seiner Verwaltung. Der in Kambodscha vorherrschende Theravada-Buddhismus wurde durch die neuen Herrscher verfolgt, die kambodschanischen Beamten zwangsweise vietnamesiert. Aus konfuzianisch-vietnamesischer Sicht war Kambodscha ein minderwertiges „Barbarenland", dazu vorbestimmt, in Vietnam absorbiert zu werden. 1841 von Vietnam endgültig annektiert, vermochte das Land seit 1845 sich wieder an Siam anzulehnen, an eine Schutzmacht, von der es wenigstens kulturell nicht scharf geschieden war ${ }^{8}$.

Bereits im späten sechzehnten Jahrhundert hatte Kambodscha vergeblich versucht, als Gegengewicht gegen seine übermächtigen Nachbarn sich des Schutzes europäischer Mächte, der Spanier auf den Philippinen und der Portugiesen auf Malacca, zu versichern. Indessen gelang es König Norodom erst 1863, Frankreichs Protektorat zu erhalten. 1904 und 1907 ließ sich Frankreich historisch kambodschanische Provinzen von Siam abtreten und unterstellte sie administrativ in Realunion mit Kambodscha dem Ober-Residenten in Phnom Penh. Obgleich das französische Protektorat Kambodscha vor der siamesischen und vor allem vor der vietnamesischen Úbermacht rettete, so ermöglichte es doch erst die vietnamesische Einwanderung ${ }^{9}$. Denn Kambodscha wurde zusammen mit Vietnam im sogenannten „Französisch-Indochina" verwaltet. Da Südvietnam wesentlich früher unter französische Herrschaft geraten war, wurde im Dienste der Protektoratsmacht stehendes vietnamesisches Verwaltungspersonal nach Kambodscha gebracht. Auch Arbeitskräfte aus dem übervölkerten Vietnam wurden für französische Plantagenunternehmen in Kambodscha angeworben; die Kambodschaner selbst ließen sich durch keinen wirtschaftlichen Anreiz für Lohnarbeit in fremden Unternehmen gewinnen. Obligatorische, regelmäßige und dazu monotone Arbeit wurde in diesem tropischen Land als Bürde empfunden. Dem theravada-buddhistischen Heilsweg des Mitfühlens mit allem Leben und der Nichtanhänglichkeit an weltliche Güter ist das Erwerbsstreben fremd. So erschienen den bürgerlichen Franzosen und den emsigen Vietnamesen die buddhistischen Kambodschaner als mittelmäßige Landwirte, unfähige Kaufleute und unzuverlässige Arbeitskräfte. Die vietnamesische Minderheit betrachtet Kambodscha als natürliche Kolonie der Vietnamesen. Für das kambodschanische Volk von Reisbauern, Fürsten und Mönchen stellten die Vietnamesen, wie auch die Chinesen, das fehlende Bürgertum von Händlern, Handwerkern und Freiberuflichen. Nachdem ihnen die französische Herrschaft rechtliche Möglichkeiten mit wirtschaftlichem Anreiz zur Masseneinwanderung in Kambodscha gegeben hatte, haben die wirtschaftlichen Ambitionen der Vietnamesen Rücksichtslosigkeiten gezeitigt, die verletzend wirkten. Die Kambodschaner konkurrierten gewöhnlich nicht mit den Vietnamesen, sondern pflegten sich zurückzuziehen, wo diese auftraten. Viele kambodschanische Bauern gaben ihre traditionellen Siedlungsräume, selbst in manchen der fruchtbarsten Landesgebiete, angesichts der vietnamesischen Einwanderung auf. Die nach Kambodscha während der französischen Protektoratszeit eingewanderten Vietnamesen bildeten alsbald fünf Prozent der Gesamtbevölkerung. In der Hauptstadt Phnom Penh machen sie jedoch heute fast ein Drittel der Einwohnerschaft aus: Die Vietnamesen sind mehr urbanisiert als die Kambodschaner, aber auch mehr proletarisiert oder verbürgerlicht. In Kambodscha fand antifranzö-

8 M. F. Herz, A short history of Cambodia, New York 1958, S. 54 f.

9 Virginia Thompson, French Indochina, New York 1937. 
sischer Nationalismus und Kommunismus in erster Linie bei den Vietnamesen, nicht bei den Kambodschanern, Anklang, nachdem die französische Schutzmacht sich von 1940 an als unfähig erwiesen hatte, Indochina vor Japan zu schützen. Neben der kommunistisch geführten Widerstandsbewegung Vietnams standen deshalb bei Kriegsende die „Freien Kambodschaner" (Khmer Issarak). König Norodom Sihanuk sah jedoch in der Hegemonie Vietnams eine größere Gefahr als im französischen "Protektorat". So verband sich ein Teil der Khmer Issarak mit der in Vietnam operierenden Untergrundbewegung der Vietminh und ein anderer mit SiamThailand, das sich von einem Verbündeten Japans zu einem der Vereinigten Staaten gewandelt hatte. Doch Norodom Sihanuk überspielte diese Opposition, indem er von Frankreich 1949 für Kambodscha zunächst nur „interne Souveränität“, 1953 aber dann die endgültige Räumung des Landes von Frankreich erreichte. Sodann verfügte er die allgemeine Mobilmachung von Freiwilligen zur Verteidigung Kambodschas gegen eingedrungene vietnamesische Partisanen. Das Genfer Waffenstillstandsabkommen mit den Vietminh unterschrieb Kambodscha - im Gegensatz zu Laos und Südvietnam, für welche Frankreich unterzeichnete in eigenem Namen und als souveräner Staat: Im Februar 1954 waren die noch unter französischer Kontrolle stehenden Ressorts an Kambodscha übergegangen, so daß es früher als Vietnam zur Wiederherstellung seiner vollen Unabhängigkeic gelangt war. Hatten während des vietnamesischen Unabhängigkeitskrieges in den Jahren 1946-1954 die Operationen der Vietminh in Kambodscha noch taktischen Zielen gedient, so wurde das Land während des folgenden Jahrzehnts selbst eines der Fernziele der nordvietnamesischen Strategie, nämlich Kambodscha vom kommunistischen Vietnam abhängig zu machen. Aber gerade die offensichtliche Abhängigkeit der kommunistischen Minderheit vom vietnamesischen Erbfeind machte die Kambodschaner weitgehend immun gegen kommunistische Einflüsse.

\section{Versuche einer Außenpolitik des Gleichgewichts}

Um die "linke“ Opposition parteipolitisch überbieten zu können, verzichtete Norodom Sihanuk im Frühjahr 1955 auf den Thron und gründete eine Volkssozialistische Partei („Sangkum Reastr Niyum“). Noch in den Wahlen desselben Jahres errang seine Partei sämtliche Parlamentssitze ${ }^{\mathbf{1 0}}$. Prinz Norodom Sihanuk faßt die Verbindung des traditionellen Königscharisma mit wohlfahrtsstaatlichem Sozialismus als Fortsetzung der Traditionen des mittelalterlichen Kambodscha auf. Als „Kambodschanischer Sozialismus" hat diese Staatsideologie eine eigene Bezeichnung gefunden. Dabei wird geltend gemacht, daß Kambodscha weder Feudalismus noch Kapitalismus hervorgebracht habe und einem Eigenweg zum Sozialismus folge. Das theravada-buddhistische Königtum, zu dem sich seine Herrscher seit dem vierzehnten Jahrhundert bekennen, habe wirtschaftliche Wohlfahrt sichern sollen, um allen die Muße zur Meditation für den Nirvana-Heilsweg zu gewährleisten ${ }^{11}$. Nach einer offiziellen Formulierung der Staatsideologie Norodom Sihanuks bildet der Buddhismus einen Eckstein beim Aufbau des Kambodschanischen Sozialismus. In dieser Programmatik wird der Buddhismus geradezu als "Sozialismus" aufgefaßt - im Sinne seines Heilsstrebens nach universaler Leidensüberwindung. Ohne einen Namen für dieses Ethos gehabt zu haben, soll das traditionelle Kambodscha in diesem Sinne einen Sozialismus praktiziert haben ${ }^{12}$. Damit wird auch begründet, warum es in der Gegenwart keines importierten Marxismus' bedürfe.

All dies beschränkt weitgehend die Wirkungsmöglichkeiten der Kommunisten in der kambodschanischen Innenpolitik. Die Vorposten Nordvietnams erhielten in den Wahlen von 1955 nur drei Prozent der Stimmen. Seitdem behauptet die

10 Claude-Gilles Gour, Institutions constitutionelles et politique du Cambodge, Paris 1965.

11 E. Sarkisyanz, Buddhist backgrounds of the Burmese Revolution, Haag 1965, Kapitel 7, 9, 10.

12 Royaume du Cambodge, Considerations sur le socialisme khmere, o. O., o. J., S. 3-6. 
krypto-kommunistische Pracheachon-Partei, sie folge der Führung des Prinzen Sihanuk. Dahinter verbirgt sich jedoch wohl das Bemühen, an seinem Massenanhang zu partizipieren. Sihanuk hat jedoch - trotz des gegenteiligen Anscheins - keine Illusionen darüber, welche Ziele das kommunistische Vietnam in Kambodscha verfolgt. Auf der anderen Seite schreckte der Zerfall von Laos Kambodscha davor ab, sich an eine der Großmächte anzulehnen und damit Gefahr zu laufen, in deren Rivalitäten miteinbezogen $\mathrm{zu}$ werden ${ }^{13}$. Kambodschas Stellung $\mathrm{zwischen}$ den Machtblöcken wird von seinem Bewußtsein der Gefährdung durch das chinafeindliche Thailand, vor allem aber der Gefährdung durch die Übermacht eines expansiven Vietnams bestimmt. Denn die geographische Lage Kambodschas, bedingt dadurch, daß sich Unterland und Delta des wichtigen Handelsweges Mekong auf südvietnamesischem Staatsgebiet befinden, bringt es mit sich, daß sich Kambodscha ständig einer potentiellen Bedrohung seitens seines südvietnamesischen Nachbarn ausgesetzt sieht. In französischer Zeit gingen seine Aus- und Einfuhren über südvietnamesische Häfen. Der seit den 1950er Jahren mit französischer Hilfe erbaute kambodschanische Hafen Sihanukville vermag bisher diese nicht voll zu ersetzen. Dazu kommt, daß die militärische Aufrüstung Südvietnams seitens der Vereinigten Staaten seit 1954 die traditionelle Furcht vor der vietnamesischen Ubermacht noch erhöht hat ${ }^{14}$.

Schon am 20. Mai 1954, unmittelbar nach dem militärischen Zusammenbruch Frankreichs im Indochinakrieg, ersuchte Kambodscha die USA um den Abschluß einer Militärallianz zum Schutz gegen jede Aggression ${ }^{15}$. Im Manila-Protokoll vom September 1954 wurde jedoch die amerikanische Verteidigungsbereitschaft auf den Fall eines k o m m u n is t is chen Angriffs beschränkt. Nachdem Kambodscha keine allgemeine Beistandszusicherung von den Vereinigten Staaten erhalten konnte, glaubte es, in der Neutralitätspolitik des Gleichgewichts ein Mittel gefunden zu haben, das die potentielle Bedrohung seitens einzelner Mitglieder des einen Mächteblocks durch die Aussicht auf das Eingreifen von Staaten anderer Mächteblocks ausgleicht. So meinte Norodom Sihanuk 1956, daß man eine Hand zum Westen und die andere zu den kommunistischen Mächten ausstrecken müsse, und 1960 erklärte er noch deutlicher, „falls Kambodscha Ziel eines Angriffs der Vietminh und der Chinesischen Volksrepublik würde, könnte es die Hilfe der Freien Welt und der Vereinigten Staaten erbitten. Und wenn die Aggression von Thailand oder Südvietnam ausginge, dann würde Kambodscha den kommunistischen Block und besonders die Chinesische Volksrepublik um Hilfe ersuchen."16 Kambodschas Neutralitätspolitik ging zwar von einer strikten Ablehnung von Interventionsansprüchen beider Blöcke aus, setzte jedoch gleichzeitig deren Existenz als reale Möglichkeit voraus. Die Politik Kambodschas war damit weniger das Beispiel einer klassischen Neutralitätspolitik, als vielmehr das einer klassischen Gleichgewichtsund Allianzpolitik, welche die eigene Souveränität durch die Pflege zweier konträrer Allianzprojekte sichert, aber die endgültige Entscheidung für eine der beiden Möglichkeiten hinausschiebt, bis eine unmittelbare Bedrohung erfolgt. Die SEATO bot Kambodscha die Möglichkeit der Abschreckung einer nordvietnamesischen, das kommunistische China die Möglichkeit der Abschreckung einer südvietnamesischen oder siamesischen Aggression. Allerdings war eine Grundvoraussetzung dieses Konzepts kambodschanischer Neutralität gewesen, daß die Konfrontation zwischen dem angrenzenden südlichen Vietnam und Thailand einerseits und China andererseits erhalten blieb. Thailands historische Feindschaft erhielt für Kambodscha bereits 1958 aktuelle Bedeutung, als die thailändische Regierung die Rückgabe der 1904 und 1907 von Frankreich annektierten, mit Kambodscha zunächst administrativ, seit der Unabhängigkeit voll eingegliederten Territorien verlangte. Die

13 Vgl. R. Smith, Cambodia's foreign policy, Ithaca (USA) 1965.

14 E. Sarkisyanz, Südostasien seit 1945, München 1961, S. 43.

15 E. M. Szaz, „Cambodia's foreign policy “, in: Far Eastern Survey, XXIV (Oktober 1955), S. 154 ff.

16 M. Leifer, Cambodia. The search for security, London 1967, S. 82. 
diplomatischen Beziehungen standen kurz vor dem Abbruch, und die Grenzen wurden geschlossen. Im folgenden Jahr wurde die Teilnahme sowohl Thailands als auch Südvietnams an Verschwörungen zum Sturze des kambodschanischen Staatschefs aufgedeckt, wobei angeblich auch die amerikanische Central Intelligence Agency (CIA) ihre Hand im Spiel gehabt haben soll. Als Thailands Diktator, Sarit Thanarat, sein Verhältnis zum Prinzen Norodom Sihanuk von Kambodscha mit demjenigen zwischen Tiger und Schwein verglich, wurden die diplomatischen Beziehungen endgültig abgebrochen. Eine Satisfaktion erhielt Kambodscha erst, als 1962 der Internationale Gerichtshof im Haag das von Thailand besetzte umstrittene Gebiet um den Prah-Vihar-Tempel ersterem zusprach. Auch kambodschanische Befürchtungen, Thailand könnte sich mit China aussöhnen, erwiesen sich als grundlos, als der prowestlich eingestellte Thanom Kittikachorn dort die Macht übernommen hatte. Auf der anderen Seite kam es seit 1958 an der kambodschanisch-südvietnamesischen Grenze zu Zwischenfällen. Sie wurden von der Internationalen Waffenstillstandskontrollkommission regelmäßig auf südvietnamesische Übergriffe zurückgeführt. Als der kanadische Vertreter der Internationalen Kontrollkommission dennoch eine Verurteilung Südvietnams als Aggressor verhinderte, antwortete Kambodscha im Juni 1958 mit der Aufnahme diplomatischer Beziehungen zum kommunistischen China ${ }^{17}$. Im darauffolgenden November schloß es ein Handelsund Zahlungsabkommen mit Nordvietnam ab. Südvietnam hatte die Verletzung der kambodschanischen Grenze durch seine Truppen damit begründet, daß Kambodschas Territorium als Stützpunkt für nordvietnamesische Partisanen diene, die dort ganze Sammellager unterhielten. Als Kambodscha daraufhin die Internationale Kontrollkommission und einen angesehenen Berichterstatter der „New York Times" aufforderte, das fragliche Gebiet in Augenschein zu nehmen, fanden diese neutralen Beobachter keine Stützpunkte auf kambodschanischem Gebiet. Sie bestätigten vielmehr die Darstellung der kambodschanischen Regierung, daß sie in den Grenzen ihrer militärischen Mittel die Benutzung ihres Territoriums kommunistischen und anderen ausländischen Streitkräften verwehre ${ }^{18}$. Dennoch haben auch danach südvietnamesische und amerikanische Truppen bei der Verfolgung der Vietcong wiederholt die Grenze Kambodschas überschritten. Noch im Juli 1965 stellte die Internationale Kontrollkommission fest, daß im Jahre 1964 und in den ersten fünf Monaten von 1965 Streitkräfte der Regierung Südvietnams die Grenzen Kambodschas $375 \mathrm{mal}$ verletzt haben. Einstimmig stellte diese Kommission auch fest, daß in keinem einzigen Fall Kambodscha diese Zwischenfälle verschuldet habe. $\mathrm{Zu}$ demselben Ergebnis kommt der Kommissionsbericht vom Oktober 1965, der eine weitere Aufzählung von Zwischenfällen enthält ${ }^{19} .1965$ und danach haben wiederum von der kambodschanischen Regierung eingeladene amerikanische Journalisten sich durch Augenschein davon überzeugt, daß die nordvietnamesische Infiltration von Partisanen nach Südvietnam nicht auf einem angeblichen „SihanukPfad" durch Kambodscha geführt wird20, wie von südvietnamesischer Seite behauptet wurde.

Gerade das entsprechende Schicksal von Laos, von dessen Ostgebieten ein großer Teil unter der "De-facto"-Herrschaft der von Nordvietnam abhängigen Pathet Lao steht ${ }^{21}$ und über dessen „Ho-Chi-Minh-Pfad“ im wesentlichen die Infiltration von Nord- nach Südvietnam erfolgt, veranlaßte Norodom Sihanuk, internationale Garantien für die Neutralisierung Kambodschas als Pufferzone zwischen den feindlichen Blöcken in Südostasien zu fordern. So ersuchte er alle an der Genfer LaosKonferenz von 1962 beteiligten Staaten, mit Ausnahme Thailands, Kambodscha eine solche Garantie zu geben wie sie Laos, als Alternative zur nordvietnamesischen

17 Ibid., S. $97 \mathrm{f}$.

18 R. Trumbull, The scrutinable East, New York 1964, S. 181-185; New York Times, 14. 10.1965

19 The Asian Recorder, Juli, Oktober 1965.

20 Leifer, op. cit., S. 180.

21 A. J. Dommen, Conflict in Laos, London 1964. 
Totalhegemonie, auf dieser Konferenz erhalten hatte. Aber nur die kommunistischen Staaten und Frankreich erklärten sich zu diesem Zeitpunkt dazu bereit, nicht aber Großbritannien und die USA, ja nicht einmal Indien und Birma. Die offizielle amerikanische Stellungnahme lautete dahin, daß sich eine internationale Konferenz darüber erübrige, da nicht die Vereinigten Staaten Neutralität und Unabhängigkeit Kambodschas bedrohen; Norodom Sihanuk machte aber mit monotoner Regelmäßigkeit - vielleicht um die Teilnahme Chinas gegen Kambodschas Erbfeinde zu gewinnen - gerade die Vereinigten Staaten für die südvietnamesischen Einfälle in sein Territorium verantwortlich und warnte 1964, daß seine Streitkräfte Widerstand leisten würden. Bald schon schoß kambodschanische Artillerie ein amerikanisches Flugzeug ab, das Kambodschas Luftraum verletzt hatte. Und im Dezember 1964 erklärte Norodom Sihanuk, daß Kambodscha bedroht sei, und zwar durch Südvietnam, Thailand, die SEATO-Allianz und die (aus den Khmer Issarak hervorgegangene) Khmer-Serai-Oppositionsgruppe, die von den Vereinigten Staaten gelenkt werde und von der CIA ausgerüstet worden sei ${ }^{22}$. Eine amerikanische Erklärung, daß Streitkräfte der USA (und Südvietnams) die Verfolgung des Feindes auch auf kambodschanisches Territorium tragen würden, schien in den ersten Tagen des Jahres 1966 Kambodscha in den Vietnam-Krieg zu ziehen, dort aber auf die Seite der Kommunisten. Schließlich wurde jedoch von den amerikanischen Stellen zugegeben, daß Kambodscha nicht Helfershelfer der Vietcong sei, und erklärt, daß man nicht seine Grenze verletzen, sondern bloß „in taktischen Situationen das Feuer (von dort?) erwidern " würde. Allerdings bestanden die Vereinigten Staaten nach wie vor darauf, daß Kambodscha mit Thailand und Südvietnam, den Verbündeten der USA, von denen es sich bedroht fühlt, direkt verhandeln und nicht die westlichen Großmächte durch Bestehen auf Garantieerklärungen in seine Lokalangelegenheiten hineinziehen solle. Norodom Sihanuk hatte deshalb schon 1964 für den Fall, daß die Vereinigten Staaten eine Neutralisierung Kambodschas weiterhin nicht akzeptieren würden, mit einem Bündnis mit China gedroht. Als die entsprechende amerikanische Garantie verweigert wurde, plünderte eine Volksmenge die Gesandtschaften und Informationssäle der Vereinigten Staaten und Großbritanniens. $\mathrm{Zu}$ diesem Antagonismus soll das persönliche Verhalten des ersten amerikanischen Gesandten in Kambodscha, Robert McClintocks, nicht wenig beigetragen haben. So soll er den damaligen König Sihanuk so behandelt haben, „wie es sich einem Manager der United Fruit Company gegenüber einem Präsidenten einer Bananen-Republik geziemt haben mag“"23. Von Amerikanern und in Amerika hat Norodom Sihanuk sich wiederholt gedemütigt gefühlt. So hatte im April 1965 das Nachrichtenmagazin „Newsweek" im Ernst berichtet, daß seine Mutter, die Königin, Bordellbesitzerin sei. Ein großer Teil der amerikanischen Presse, vor allem "Time" hatte - wohl aus der puritanischen Vorstellung heraus, daß Neutralisten als unmoralische Menschen anzusehen seien - ein lächerliches Bild von dem kambodschanischen Herrscher vermittelt. Er wurde als Saxophon-Spieler, JeepFahrer und Playboy dargestellt. Bei seinem Besuch in New York im Herbst 1960 wurde sein Wagen von der Polizei angehalten, um Chruschtschow Platz zu machen. Des weiteren zwang die New Yorker Polizei den Wagen des kambodschanischen Prinzen, hinter den Autos des kommunistischen Diktators von Ungarn, Kadar, herzufahren. So in einer Reihe mit kommunistischen Staatsmännern der Ơffentlichkeit präsentiert, wurde Sihanuk gleich jenen von der New Yorker Bevölkerung mit Mißfallenskundgebungen bedacht. Im übrigen hielt man ihn in New York für einen kommunistischen Diplomaten aus Asien, und zwar im Range eines jungen Botschaftssekretärs. Von allen damals in New York weilenden Staatschefs erhielt Norodom Sihanuk die kleinste Eskorte24. Auch die Machthaber der Sowjetunion

22 The Times (London), 8. 9. 1965; Leifer, S. 144.

23 Leifer, S. 103.

24 J. P. Armstrong, Sihanuk speaks, Washington 1964; Norodom Sihanouk, Chef d'Etat du Cambodge, Rapport au peuple khmer au terme de Mission en Amérique, o. O., o. J., (Phnom Penh), Ministere de l'information, S. $21-22$. 
fanden im Oktober 1965 keine Zeit, ihn in Moskau zu empfangen, wo er den Feierlichkeiten des bolschewistischen Revolutionsjahres beiwohnen wollte. Schon 1958 hatte er feststellen müssen, daß die kommunistische Großmacht ihre Aufmerksamkeit den Großen unter den Neutralisten vorbehält. Als deren „Big Three“, Tito, Nasser und Nehru, 1956 in Brioni konferierten, ließen auch sie Norodom Sihanuk warten. $\mathrm{Zu}$ der Belgrader Konferenz der Neutralen von 1961 war seine Einladung nicht vorgesehen, und 1964 lehnte er eine solche nach Kairo ab. So haben persönliche Erfahrungen ebenso wie außenpolitische Erwägungen dazu beigetragen, daß der kambodschanische Staatschef die Einbeziehung seines Landes in die Dritte Welt der Neutralisten vermeidet, wo Kambodschas Interessen von denen der neutralistischen Großen überschattet wären, „der Nabobs der Dritten Welt, die eigene Probleme und keine Zeit für Kambodscha haben“" 25 . Nicht als "neutralistisch" sondern als "neutral" - und mit Vorliebe unter Berufung auf Finnland versteht sich Kambodschas Außenpolitik. Auch terminologisch ist damit ein Gegensatz zu den Blockfreien angedeutet. Entscheidend dürfte dabei die Erkenntnis von der Nutzlosigkeit einer Verbindung mit dem schwächsten „Block“ gewesen sein, dessen "Neutralismus“ ohnehin von beiden Lagern des Kalten Krieges beargwöhnt wird. Allerdings hat Kambodscha einer Reihe von Forderungen der neutralistischen Staaten zugestimmt, z. B. der Unabhängigkeit Algeriens, aber auch den indonesischen Ansprüchen auf West-Irian. Im Gegensatz zu diesen stimmte Kambodscha aber in den Vereinten Nationen nicht für den Ausschluß Südafrikas. Auch unterhält es volle diplomatische Beziehungen zu Israel.

Peinlich für Neutrale und Neutralisten wurde jedoch die Colombo-Konferenz vom Dezember 1962, die zu dem Zweck einberufen worden war, den Konflikt zwischen China und Indien zu schlichten. Die Furcht vor der chinesischen Großmacht erwies sich stärker als die Prinzipien von Bandung. Ähnlich wie der birmanische Militärdiktator $\mathrm{Ne}$ Win suchte der Staatschef Kambodschas, die chinesischen Aggressoren nicht durch eine Verurteilung der Aggression zu reizen. Norodom Sihanuk legte den beiden Parteien nahe, sich näherzukommen. In der Hoffnung, einmal auf Chinas Schutz zurückgreifen zu können, stellte sich Kambodscha an der Seite Chinas auch gegen den Atomteststoppvertrag vom August 1963 und forderte statt dessen eine Weltkonferenz zur Generalabrüstung, wie sie auch von China verlangt wurde. Norodom Sihanuk erklärte seine Haltung so: „Wir ziehen es vor, mit China isoliert, statt gegen China isoliert zu werden ... ${ }^{\text {"26 }}$ In diesem Sinne stimmte Kambodscha in den Vereinten Nationen im Juni 1965 gegen eine von Indien eingebrachte Resolution zur Verurteilung der Atomversuche. Sogar das Einvernehmen mit der Sowjetunion, einer der beiden Ko-Vorsitzenden der Genfer Indochina-Konferenz von 1954, wurde von Kambodscha um der Freundschaft Chinas willen, aufs Spiel gesetzt.

\section{Die Grenzen der Neutralität und die Rückversicherung auf China}

Kambodschas Außenpolitik der 1960er Jahre sieht in China in erster Linie eine Macht, welche ein wiedervereinigtes Vietnam in Schranken halten könnte. Während Kambodscha in den Jahren 1955-1960 vor allem von der Möglichkeit ausgegangen war, daß die Vereinigten Staaten ihre Verbündeten Thailand und Südvietnam von einer Expansion auf Kosten Kambodschas abhalten könnten und deshalb die Amerikaner für die Übergriffe dieser ihrer Verbündeten verantwortlich machte, hält Norodom Sihanuk seit dem Fiasko der USA-freundlichen Militärpartei in Laos (1960-1962) die amerikanische Regierung nicht mehr unbedingt für willens, oder imstande, selbst ihre eigenen Verbündeten in Südostasien wirksam gegen die kom-

25 Cambodian Commentary (Phnom Penh), Oktober/Dezember 1961, S. 57; Norodom Sihanouk, Rapport au peuple ..., S. 45-54.

26 Leifer, S. 141 .' 
munistischen Mächte zu verteidigen. Dementsprechend erstrebte Kambodscha wenigstens zeitweilig nicht mehr Sicherheit durch eine Gleichgewichtspolitik zwischen den rivalisierenden Blöcken, sondern suchte sich durch Anlehnung an China für die Zeit des endgültigen Abzuges der Amerikaner aus Südvietnam abzusichern - so wie es sich auch nach dem Rückzug Frankreichs im Jahre 1954 auf die Vereinigten Staaten zu stützen suchte. Die einzige Hoffnung, der Kolonisierung durch ein wiedervereinigtes Vietnam zu entgehen, sah Sihanuk in der chinesischen Schutzmacht, die sozusagen den Platz der französischen Protektoratsmacht im Sinne des Vertrages von 1863 einnehmen sollte, gleichsam als Alternative des geringeren Úbels gegenüber einer künftigen vietnamesischen Hegemonie. Norodom Sihanuk suchte damit Sicherheit gegenüber dem kommunistischen Vietnam beim kommunistischen China, da ja historisch gesehen das vietnamesische Verhältnis zu China nicht immer harmonisch gewesen ist. Aber schon Champa, das kulturell Kambodscha verwandte Reich des Mittelalters, das dann aber vietnamesischer Südexpansion zum Opfer fiel, hatte traditionell bei China, dem mächtigen nördlichen Nachbarn des feindlichen Nachbarn, Schutz gesucht. So sah Norodom Sihanuk in einer Art Erneuerung der traditionellen Souzeränität des fernen China über Südostasien eine Alternative zur Unterwerfung Kambodschas durch Vietnam. Seinen zur Nachfolge vorgesehenen Sohn ließ er in der Chinesischen Volksrepublik ausbilden und erklärte: „Dies habe ich immer ausgesprochen, am Tage, an dem unser Königtum durch die Gewalt des Volkswillens oder durch internationale Gegebenheiten aufhören würde, ein harmonisches und nutzbringendes Gebilde zu sein, würde ich nicht zögern, selbst die Initiative zu ergreifen, es zu opfern, um die Nation auf andere Wege zu führen, ihr helfend, in Frieden und ohne Blutvergießen die Revolution ihrer Wahl zu vollziehen. "27 In der Periode der Strukturwandlung des Kommunismus in Asien glaubt Sihanuk anscheinend, daß Kambodscha seine Identität bewahren könnte. Vielleicht glaubt er aber auch, daß der Kommunismus in einer ferneren Zukunft in Asien seine Expansionsdynamik verlieren werde. Um jedoch inzwischen China an der Beschützung Kambodschas zu interessieren, wird dieses Schutzbedürfnis verbal noch immer als gegen die Verbündeten der USA gerichtet dargestellt, in Wirklichkeit aber gerade gegen die Expansion eines vom Kommunismus geeinten Vietnam verstanden.

Nicht aus China, sondern aus Nordvietnam sollen deshalb - jedenfalls nach den Erklärungen Norodom Sihanuks - die Pläne der krypto-kommunistischen Pracheachon-Partei zum Sturze seiner Regierung dirigiert worden sein, Staatsstreichpläne, denen er nicht weniger Publizität angedeihen ließ als denjenigen des amerikanischen CIA. Vor diesem Hintergrund sind darum auch so offenherzige Erklärungen wie die folgende zu verstehen: „Wenn die Amerikaner sich zurückziehen, ohne den Nichtkommunismus (sic) und die territoriale Integrität Südvietnams garantiert zu haben, dann wird sich Kambodscha entlang seiner ganzen Ostgrenze dem Kommunismus von Angesicht zu Angesicht gegenübersehen. Dies wird für Kambodscha sehr gefährlich sein, da es nicht wünscht, kommunistisch zu werden. Und für uns in Kambodscha ist von allen möglichen Kommunismen der vietnamesische Kommunismus am schlimmsten. ${ }^{28}$ Das kommunistische Vietnam hat sich dann auch tatsächlich lange geweigert, die Grenzen Kambodschas mit Südvietnam zu garantieren. Der nordvietnamesische Außenminister, Pham Van Dong, verwies insoweit die kambodschanische Regierung an die südvietnamesische „Befreiungsfront", nicht ohne anzudeuten, es wäre Sache der vietnamesischen Kommunisten und nicht der Kambodschaner, die Grenzziehung zu bestimmen. Auch die Forderung Kambodschas, seine Grenzen gegenüber Vietnam dadurch zu schützen, daß an diesen eine Friedenstruppe der Internationalen Kontrollkommission stationiert werde, mußte es mit Rücksicht auf Vietcong-Interessen aufgeben. Ein weiteres

27 Armstrong, Sihanuk speaks.

28 New York Times, 7. 2. 1965; Sunday Times (London), 16. 5. 1965. 
kambodschanisches Ersuchen vom 25. Juni 1966, das sich nur auf die Verstärkung der Internationalen Kontrollkommission an dieser Grenze bezog, ist durch die Sowjetunion in ihrer Eigenschaft als Ko-Vorsitzende der Genfer IndochinaKonferenz torpediert worden. Schon im Vorjahr haben die Vietcong auf der in Kambodscha tagenden Konferenz der Völker Indochinas Norodom Sihanuk daran gehindert, seine Forderung nach Neutralisierung Kambodschas in einer Rede vorzutragen $^{29}$. Denn seit 1965 kommt der Hauptwiderstand gegen eine internationale Konferenz zur Neutralisierung Kambodschas und zur Garantie seiner gegenwärtigen Grenzen nicht mehr von amerikanischer, sondern von kommunistischer Seite - eine unmittelbare Folge des Vietnam-Krieges. Wegen der militärischen Situation in seinem Nachbarland und der sich daraus ergebenden politischen Aussichten sieht sich Kambodscha auch nicht mehr in der Lage, einer solchen Konferenz unter nicht-kommunistischen Bedingungen zuzustimmen: Bereits am 1. Mai 1965 war Kambodscha gezwungen, einen entsprechenden britischen Gegenvorschlag abzulehnen und den Ausschluß der Regierung Südvietnams von einer solchen Konferenz zu verlangen. Wenn schon die Auflösung Südvietnams, das Kambodscha von der nordvietnamesischen Übermacht trennt, den Spielraum der Außenpolitik Sihanuks so einschränkt, ist es ziemlich offensichtlich, was die Konsolidierung eines von den Kommunisten geeinten Vietnam für Kambodscha bedeuten würde. So hat der kambodschanische Regierungschef in einem privaten Gespräch mit dem Chefminister von Sarawak 1966 ganz offen erklärt, daß er es vorziehen würde, wenn Vietnam weiterhin geteilt bliebe. Dabei macht Norodom Sihanuk keinen Unterschied zwischen einem kommunistischen oder einem nicht-kommunistischen Vietnam, als er sagte: „Ob er Kaiser Gia Long, Ho Chi Minh oder Ngo Dinh Diem heißt, kein Vietnamese wird friedlich ruhen können, bis er Kambodscha in die Vernichtung getrieben hat, nicht ohne es vorher durch das Stadium der Sklaverei getrieben zu haben." ${ }^{30}$ Gerade im Hinblick auf den sich inzwischen abzeichnenden Ausgang des Vietnam-Krieges müssen die Worte von Norodom Sihanuk (in einem Interview mit der Ceteka - Tschechoslowakischen Telegraphenagentur - vom Jahre 1960) über Kambodschas Haltung zum kommunistischen Nordvietnam zitiert werden: „... Man kann nicht wirklich die Aufrichtigkeit oder den Pazifismus eines Staates beurteilen, bis seine Grenzen sich mit den eigenen berühren ..." ${ }^{31}$

\section{Anmerkung der Redaktion}

Die Zeitschrift will nicht nur analysieren, sondern zugleich auch über die wichtigsten Entwicklungen informieren. Da der Verfasser des vorstehenden Aufsatzes sich seit 1968 zu Studien am East-West Centre von Hawaii aufhält, war es ihm nicht mehr möglich, die jüngste Entwicklung der kambodschanischen Außenpolitik in sein Manuskript einzuarbeiten. Die Redaktion hat daher Herrn Dr. M. Y. Cho um die folgende Darstellung gebeten.

Die jüngste Entwicklung der kambodschanischen Außenpolitik:

In Anbetracht der Möglichkeit eines absehbaren Endes des Vietnam-Krieges, die seit 1967 erkennbar wurde, versuchte Sihanuk, auch das Verhältnis zu Nordvietnam $\mathrm{zu}$ verbessern. In jüngster Zeit scheint er ein Gleichgewichtssystem mit drei rivalisierenden Staaten zu erstreben: China gegen Vietnam und die USA, die USA gegen Vietnam und China, Vietnam gegen China und die USA ${ }^{32}$. Schon unmittelbar

29 Cambodge, Ministère d'Information, Discourse de Norodom Sihanouk Upayuvareach, Chef de l'Etat du Cambodge, a l'occasion de l'ouverture de la Conférence des peuples indochinoises, Phnom Penh, 25.2. 1965.

30 Kambuja, 1. 4. 1966, S. 26, zitiert bei Leifer, S. 188; Cambodia News, Januar 1963, S. 4; Phnom Penh Presse, 24. 6. 1966.

31 Royaume du Cambodge, Principaux discours ... de ... Norodom Sihanuk en 1960, o. O. (Phnom Penh?) u. J., S. 166

32 Als Quellen für die jüngste Entwicklung wurden herangezogen: Asahi Nenkan ("Asahi-Jahrbuch“), 1967 und 1968, Tokio; Europa-Archiv; Summary of World Broadcasts (BBC), London; Far Eastern Economic Review, Hongkong; Realités Cambodgiénnes, Phnom Penh; Le Monde, Paris. 